\title{
Architectural Approach to Application of Reinforced Soil in the Structure of Bridges and Urban Overpasses
}

\author{
Gholamreza Pour Ebrahim ${ }^{1}$, Omid Pourebrahim ${ }^{2, *}$ \\ ${ }^{1}$ Civil Engineering Department, Shahid Bahonar University of Kerman, Kerman, Iran \\ ${ }^{2}$ Architecture Department, PNU Hormozgan, Hormozgan, Iran
}

\section{Email address:}

pourebrahim.omid@gmail.com (O.Pourebrahim)

\section{To cite this article:}

Gholamreza Pour Ebrahim, Omid Pourebrahim. Architectural Approach to Application of Reinforced Soil in the Structure of Bridges and Urban Overpasses. International Journal of Science, Technology and Society. Special Issue: Research and Practice in Architecture and Urban Studies in Developing Countries. Vol. 3, No. 2-1, 2015, pp. 70-74. doi: 10.11648/j.ijsts.s.2015030201.24

\begin{abstract}
In recent years, population growth along with entering various kinds of cars in human life led to increasing the intercity trips, the trips that are not proportional with traffic capacity of streets especially intersections. This caused problems in the transportation. One of the solutions to this problem is to build bridges and roadway overpasses so that their applying in addition to flowing traffic, landscaping and creating green spaces has least effects on the architecture structure of the place. Application of reinforced soil is one of the appropriate and modern methods in this field. In this method a combination of elastic elements such as soil and geosynthetic (e.g., network fibers and polymer tissues) is used and huge soil bodies are created for path in an optimal desired shape. One of the precious advantages of this method is use of soil which is a natural and inexpensive element with the capability of growing plants. In this paper, we will review on types of bridge and overpass architecture in terms of topology and beautification, then besides stating the reinforced soil properties its functional potential in the field of making architecture structure will be discussed. Hoping that in this way architects can improve their intellectual creativity in this regard.
\end{abstract}

Keywords: Grade Separation, Interchange, Reinforced Soil, Architecture, Landscaping

\section{Introduction}

Population growth, uncontrolled urban development and entering different types of vehicles in recent years have increased the demand for intercity and between city trips which considering the limitations of traffic network (roads, streets, etc.) have led to use grade separations at the junctions of the streets. Since these junctions can be seen in almost every high-traffic and important locations of cities, necessity of Architecture and Municipalize attitude to them in terms of harmony with the environment, green space creation and beautification is inevitable. Since the path of vehicles at grade separations should have three-dimensional curves and arcs and optimum space, whatever the materials used in their construction have more capability of forming, durability and compatibility with the environment and the potential for plant growth and development of green space architects can better present their ideas. One of the most desirable methods in this field is soil reinforcement (or reinforced soil) in which a combination of soil and resistant elastic elements (ductile) such as fibers, lattice planes (geogrid or geonet) and geotextile polymers is used. In addition to ductile properties and green space creation capability, being natural and inexpensive are another advantages of soil which constitutes the main bulk of grade separation. In this paper, we briefly review the introduction of reinforced soil method, then the need for construction, traffic function, Formant structure and architecture structure of different types of grade separation and the capability of the soil method in designing and establishing atmosphere will be expressed. Hope that through this we could take a step, however small, in the provision of architectural creativity, beautification, creating green spaces and refreshing cities.

\section{Definition of Reinforced Soil}

From the beginning of civilizations soil as one of the construction materials has been used in various fields, especially road construction. However, due to its weakness of tensile strength and lack of shear strength researchers have 
constantly been trying to improve its properties and increase its resistance and used various methods such as mechanical modification (e.g. density), chemical modification (e.g. the use of lime) and reinforcing it (use of resistant and elastic materials to create a coherent linkage between soil particles). Undoubtedly reinforced soil method is one of the modern solutions in the field of reinforcement and strengthening of land and building structures and soil bodies such as; roadbeds and grade separations, which has been used more and more in the recent century. In this method, appropriate elastic and environmentally elements are used in order to improve soil engineering properties such as tensile and shear strength and ductility, and consequently a composite, resistant and ductile environment will be created [9].

\section{History}

Application of auxiliary components and elements in soil and other building materials reinforcement has always been of significant notice. The origin of the idea of this application can be found in natural samples and patterns. For example, many animals, especially birds, mix wood pieces and parts of plants with mud and use it in nesting, or in steep slopes in the nature with plant taken root on them which are resistant against slide and instability. Using chaff and straw in mud reinforcement (thatch mortars), placing some trees components such as palm trees in foundation of structures application of leaves to sustain bed and besides of waterways in agriculture have been common since ancient times and also is still used. [9]

In the last century, the emergence of new materials, especially polymers and the need to build important soil structures like the highways, grade separations, embankment dams, etc. have caused the emergence of reinforced soil method and theories about it.

In the history of reinforced soil Andre Cayon in 1929 designed the first Palisade wall anchored (reinforced soil walls). The wall comprises of two main parts including (shell) or the front soil protector section and tensile elements attached to them which are anchored in back soil. Figure 1 shows the scheme of the wall.
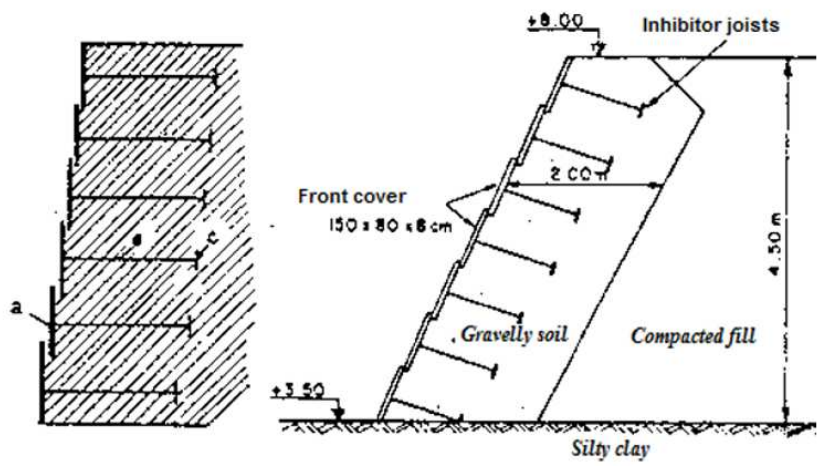

Figure 1. (A)Schematic Figure - (B)Reinforced soil wall ladder

In the early 1960s, Henry Vidal provided the first report on the theoretical principles and practical methods for soil reinforcement which caused rapid expansion of the reinforced soil subject. In that report, he introduced the reinforced soil as a new type of composite materials. He also in his first scientific article in 1964, proposed a comprehensive theory about the different ways to create a coherent environment using pieces, incoherent grains and strands of fibers. Lee et al (1973) are among the first scholars who have researched on the reinforced soil. Gray and Rafeai (1987) did some tests on sand mixed with polymer fibers and found that adding fiber increases the strength and ductility of this type of soil. Arenzic and Chowdhury (1988) in vitro studies examined the first physical model of a reinforced soil retaining wall. Michalowski and Zao (1996) defined a mathematical model with reinforced sand and reinforcement fiber based on the behavior of composite materials. Wang et al (2000) in addition to density tests of polymer fibers also tested polymer fibers wt $\%$ effect on density, resistance, and ductility of clayey sand. In recent years in our country by producing a variety of reinforcement elements such as Geogrid, as well as the efforts of great masters Like Dr. Kambiz Behnia many researches were conducted in the development of using reinforced soil method in highways and intersections, and we can say that Iran is one of the few countries in the world alongside most developed countries that builds reinforced soil walls. Figure 2, shows the role of reinforced soil in landscaping.
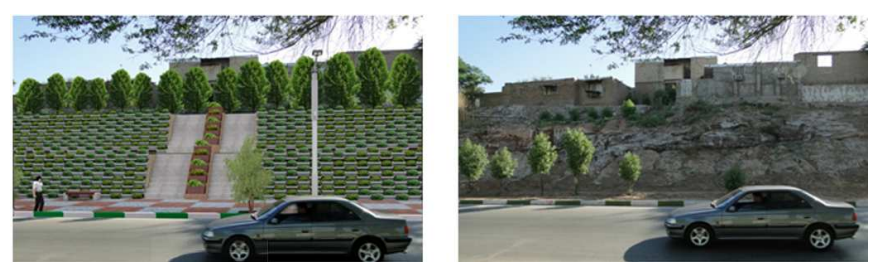

Figure 2. The role of reinforced soil in landscaping. (A)simple soil body(B)modified body with reinforced soil (from: www.Ahvaz.ir)

\section{Reinforcement Elements}

Materials that are used in the reinforcement may be made of metal, parts of plants (like straw in thatch) or Geosynthetics polymer materials. Specific properties of polymers engineering such as durability, lightness, elasticity, ductility and resistance to corrosion caused by chemical agents caused them to be easily implemented in soil reinforcement. Generally, soil reinforcement elements are used in two ways:

A) Can be located in the specific locations and directions between the soil layers in the form of intertwined layers, perforated screens, strip belts and rope-like strands, or as elements and illustrative baskets inhibit the soil from around (like sacks of soil used in trenches).

B) In the form of thin fibers or small chips that can be mixed with soil (Such as straw particles in thatch) and increase resistance, bearing capacity and ductility of the soil. Figure 3 shows examples of these polymeric elements. 


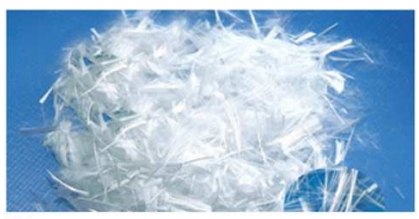

B

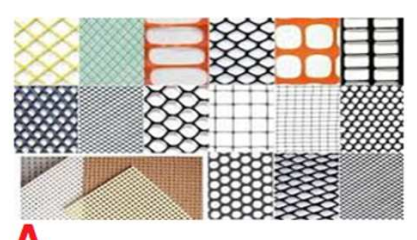

A

Figure 3. AExample of polymeric reinforcement elements. (A)Perforated screens - (B)Fibers

\section{Performance Mechanism of Reinforcement Elements in Soil}

Generally, the main cause of cohesion and stress transition in soil is phenomena of friction and adhesion between particles. In granular soils that are free of adhesion the only factor that causes shear strength is the friction force which in turn depends on the friction coefficient and effective tensions between soil particles. In a mixture of soil and fiber stress transfer mechanism between soil particles and fibers is based on the phenomenon of interactions between them. It should be explained that flow of compressive stresses on the one hand deforms the elements of the soil particles and fibers and on the other hand causes friction, to shear stresses be mobilized at the intersection of fibers and soil particles. The reaction of these stresses creates tensile forces in fibers, stretches them and causes the fibers to get involved with soil particles. Connection of these two increases the shear strength, elasticity and ductility properties of soil and fiber mixture. In short, it can be concluded that in reinforced soil environment shear and compressive strength caused by soil particles and environmental tensile strength are related to the reinforcement elements and the combination of this tension improves strength and ductility of samples. Figure 4 shows the performance of the fibers in the shear zone. [12]

As it is obvious, by cutting the soil and forming the cutting zone, the fibers that cut off this zone are placed under tension. Mobilized tensile force in fibers has two components that the perpendicular to the surface component increases the effect of friction between the grains and the tangential component directly increases shear strength in cutting surface.

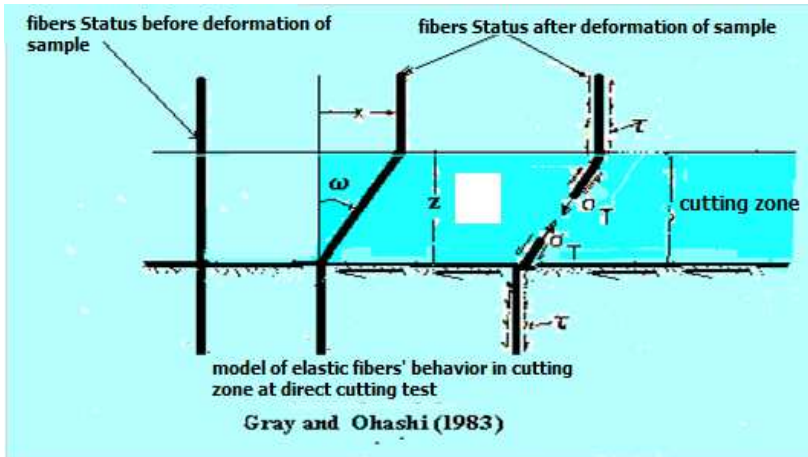

Figure 4. Behavior of tensile reinforcement elements in the under stressed soil.

\section{Grade Separation}

Generally, at a junction of the two highways or two-way streets, driver of every entering vehicle, might wish to continue to drive his/her vehicle in one of the four paths (straight, turn right, turn left, or back) [6]. Therefore the number of necessary safe paths to continue possible movements of every vehicles at junction of streets should be four times more than input paths. For example, for safe passing in an intersection of 2 two-way streets which includes four input paths either we should use an intermittent system or have sixteen free paths in order to pass without stopping. The first option leads to the application of intelligent systems such as traffic lights and also lost a lot of time (over time) and the second option requires building a proper grade separation. Obviously in case of having lots of trip demands and existence of necessary space and facilities building intersection not only increase travel speed but also prevents wasting a lot of time and energy.

Grade separations can provide vehicles' movement with safe speed and without stopping in any direction at intersections of freeways, highways and streets (three-ways, four-ways and squares). Grade separations structural difference is related to the number of paths that have been considered in the design. The simplest types of these grade separations are underpasses and overpass bridges, and the most complete types are intersections that allow traffic to move freely, with fewer interruptions in all directions using special three-dimensional curves [6]. Figure 5 shows the general scheme of some grade separations.
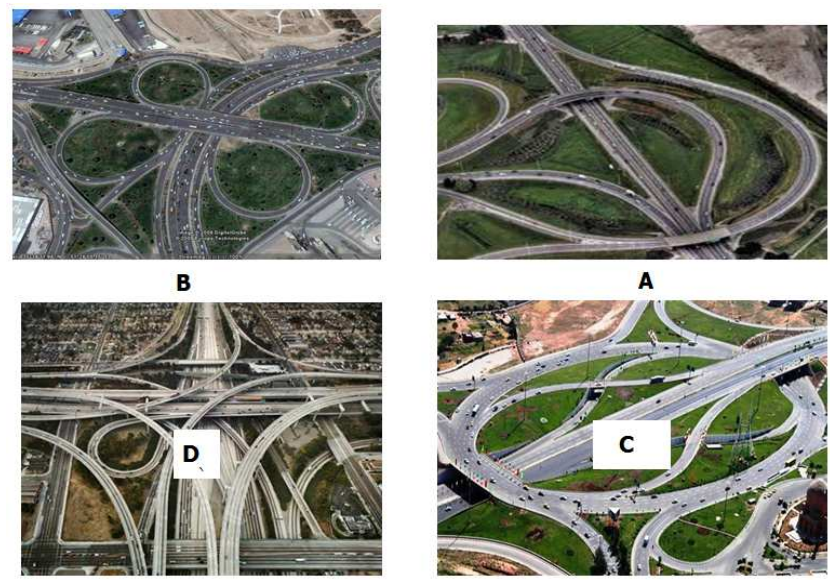

Figure 5. An example of the types of grade separations: (A), three-way, (B) four-way (from: www.tna-co.ir) (C) square (from: www.tabrizemodern.persiangig.com), (D) compound (from: www.afkarnews.ir)

\section{Types of Reinforced Soil Body Views}

In general based on used aggregates the views of reinforced soils can be divided into following types:

1) Hard view that is generally made of concrete or stone. Although it can be formed in any shape like vertical or step, but does not have the ability to create green space 
of vertical surfaces. The basis of balance and stability of the body of this view is on restraining the front shell fragments in the soil behind it. This method is used in areas with limited space such as the wall of the bridges. Figure 6 shows pictures of this reinforced soil method.

B
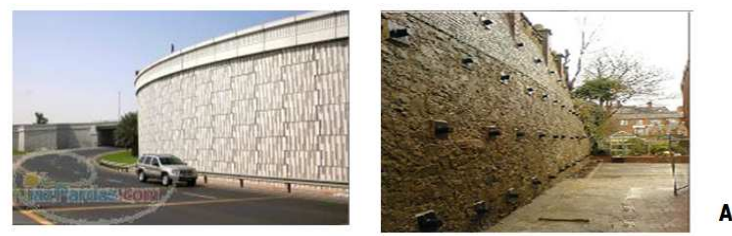

Figure 6. An example of hard views (A), stone, (B) concrete (from www.memarinews.com)

2) Soft view: the used aggregates in this type of view are mainly compacted soil that can be implemented as vertical, Slope or step view. To balance the body and prevent soil loss the polymer perforated screens (e.g. geogrid) which would be restrained in the embankment behind are used. Among the advantages of this method cheapness, work speed and ability to beautification with green space can be mentioned.

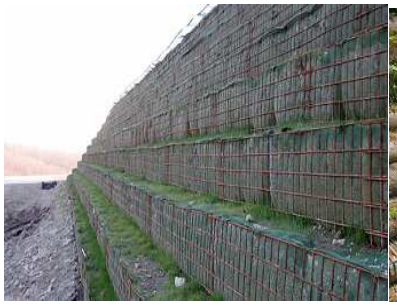

Figure 7. Examples of using soft views. www.retainingsolutions.com.au) (Left) www.akturkinsaat.com.tr)

3) Compound view: In this method by using baskets or containers full of soil and mix them together a cohesive wall will be created. These containers may be made of concrete, ceramics, polymers, rubber etc. the basis of their static is on the layout and connection of packets filled with soil and establishing weight balance of the wall. Advantage of this method is having the required potential to design and beautify the environment with low costs.
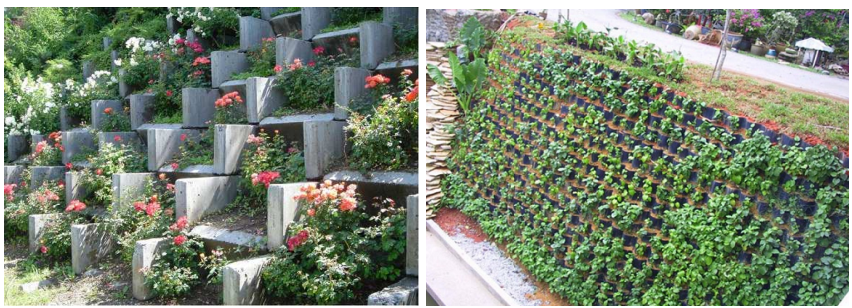

Figure 8. Examples of compound views (Right) the use of concrete blocks (from: khakemosalah.ir),(Left) the use of plastic baskets (from: www.miracell-ccs.com
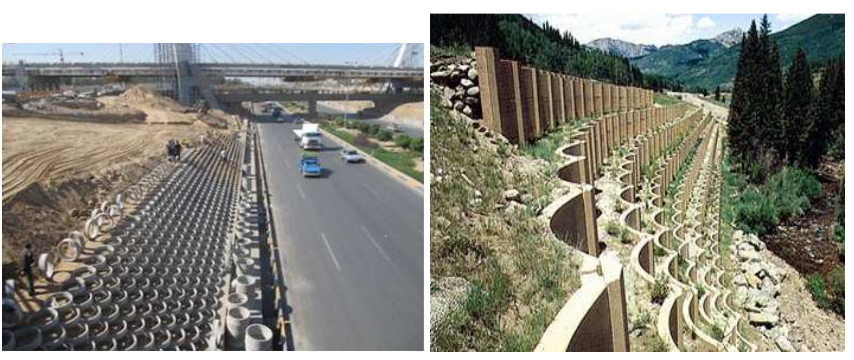

Figure 9. Examples of compound views (Right) the use of curved concrete walls (from: khakemosalah.ir) (Left) the use of concrete cylindrical parts (from: parks.mashhad.ir)

\section{Discussion and Conclusion}

By summarize the set of theoretical relationships and conducted researches in this field we can conclude that:

Reinforced soil structure primarily composed of a combination of soil and elastic and flexible reinforcement elements and when it comes to creating body of roads, bridges and grade separations is better than stone and concrete walls in designing traffic three-dimensional curved paths.

The view of reinforced soil structure is more beautiful than stone and concrete walls and is potential for architecture creativities, landscaping and creating green space. The main material used in these structures is soil that can be found in abundance everywhere. Reinforced soil structures are resistant against earthquake and impact and vibration settlements caused by traffic. Flexibility and high damping of reinforced soil walls has caused the walls to show good behavior against dynamic loads and during earthquakes and not to rupture.

Implementation of reinforced soil done with common and simple machinery and does not need any special equipment.

Compared to other walls (concrete and stone) in creating grade separation walls, cement consumption is very low and is reduced to a minimum. Despite the important role of reinforcement elements to improve the mechanical behavior of soil, the ratio consumption of these elements to soil is very negligible and at-thousandth of the weight of the soil.

Compared to concrete and stone walls the construction speed in raw reinforced bodies is very high. Although reinforced soil structures are very bulky, the excavation for the construction of these structures is often less than other weight structures, because these structures do not need massive and deep foundation and it is possible to construct them on any type of terrain. In total, in addition to greater efficiency, implementation cost of reinforced soil structures is much lower than implementation cost of walls and security buildings.

\section{References}

[1] R. J. Michelle, Translation: Behzad Kalantari, Soil Structures Engineering, University of Hormozgan, 2001.

[2] Gholam Ali Shafa Bakhsh, Gholamhossein Haddad and Mehdi Akbari, fundamentals of geosynthetic identification, University of Semnan, 2012. 

of Bridges and Urban Overpasses

[3] F. Schlosser, P. Delage, translation: Abbas Ahmed. Akhondi, Reinforced soil retaining structures and polymer materials, Building and Housing Research Center, Publication No. 242, 1998.

[4] J. K. Hiraka, translation: Mohammad Soleymani, Ahmadreza Yekani Far, An Introduction to the Principles of Urban Planning, Cultural Center of Tarbiat Modarres University Jahad Press, 1998.

[5] Saeed Monajem, route designing (railway and metro), Khajeh Nasir University of Technology, 2003.

[6] Jalil Shahi, traffic engineering, Tehran University Publishing Center, 2001.

[7] Mahyar Arabani, Traffic Engineering, University of Guilan.

[8] Mohammad Nayeb Agha, road and Traffic techniques, 1988.

[9] Hossein Ghiasian, Gholamreza Pour Ebrahim, soil reinforcement with Moquette excrement, (Ph.D. dissertation), Iran University of Science and Technology, 2004.
[10] Juarn, I. and Christopher, B. (1989) "Laboratory model study and geosynthetic reinforced soil retaining walls." Vol. 115, No. 7, pp. $905-926$

[11] Koerner,G. and hsuna,G. (1978) "Photo-intiated degradation of geotextiles" Journal of Geotechnical Engineering (ASCE), Vol. 124, No. 12, pp. 1159-1166

[12] Maher, M. H.,and Gray, D. H. (1990). "Static response of sand reinforced with distributed fibers.",Journal of Geotechnical Engineering (ASCE), Vol. 116, No. 11, pp. 1661-1677

[13] Rondoslaw, L. M,. (2000) "Secondary Reinforced for slopes." Journal of geotechnical and geonvironmental Engineering (ASCE), Vol. 126, No. 12, pp. 1166-1173

[14] Rowe, R . K.(1984) "reinforced embankment analysis and design "Journal of Geotechnical engineering (ASCE), Vol. 110 , No. 2, pp. 217-230 